УДК 811.11-112

ББК 81.2-03

DOI: https://doi.org/10.17308/lic.2020.4/3081

\title{
ФРАЗЕОЛОГИЯ ДРЕВНЕАНГЛИЙСКОГО ЯЗЫКА: ПРОБЛЕМЫ ЛЕКСИКОГРАФИЧЕСКОГО ОПИСАНИЯ
}

\author{
С. В. Мухин \\ Московский государственный институт международных отношений МИД России
}

\author{
OLD ENGLISH PHRASEOLOGY: \\ PROBLEMS OF LEXICOGRAPHIC DESCRIPTION
}

\author{
S. V. Mukhin \\ Moscow State Institute of International Relations of the Foreign Ministry of Russia
}

\begin{abstract}
Аннотация: статья посвящена анализу основных проблем лексикографического описания фразеологических единии в древнеанглийском языке и выработке конкретной методики создания фразеологического словаря древнеанглийского языка для специалистов в англистике, фразеологии и истории языка. Отмечается малая степень исследованности данной тематики в отечественном языкознании (А в зарубежном?) и вскрываются факторы такого положения вещей. В иелях практической лексикографии предложена категоризация главных проблем и последовательное рассмотрение их в четырех основных группах. В ходе исследования анализируются вопросы, касающиеся: а) параметризации фразеологического словаря, содержащего исторический материал; б) отбора словарных единиц; в) расположения отобранных фразеологических единиц; г) состава и структуры словарной статьи. Концептуально фразеологический словарь древнеанглийского языка представляется как комбинирующий черты словарей собственно фразеологического и исторического типа. Проблема отбора словарных единии решается с помощью анализа письменных памятников древнеанглийского периода и метода фразеологической идентификации. Словник составляется на основе рассмотрения облигаторных и факультативных фразеологических признаков древнеанглийских словосочетаний, а также анализа лексикографических данных существующих словарей древнеанглийской лексики. При выборе принципов расположения словарных статей предполагается следовать устоявшимся традиичям фразеографической практики. Предлагается видение структуры словарной статьи, включающей в себя ряд обязательных элементов: вокубулу, лемму, все документально зафиксированные формы фразеологизма, дефиницию и современный фразеологический эквивалент при наличии такового, несколько иллюстративных примеров контекстуального употребления и гетерохронные варианты данной фразеологической единицы в средне- и новоанглийском периодах. На основе выработанных рекомендачий составлены примеры словарных статей.

Ключевые слова: фразеология, лексикография, древнеанглийский язык, словарь, описание.
\end{abstract}

\begin{abstract}
Old English idioms. It also aims at developing a method of compiling an Old English dictionary of idioms intended for linguists specializing in the English studies, phraseology and history of English. The topic is understood to be insufficiently studied in Russian linguistics, the causes whereof are revealed in the present research. The needs of practical lexicography suggest a categorization of the main problems, which are distributed in four groups to be consecutively addressed. The research covers the following specific matters: a) defining the parameters of a phraseological dictionary featuring some evidence of historical linguistics; b) selecting the linguistic evidence itself; c) deciding on the layout of the word-list; d) composing the entries. The concept of an Old English dictionary of idioms is presumed to be based on a combination of features typical of both phraseological dictionaries proper and historical dictionaries. The task of selecting idioms is performed through analyzing old English written records
\end{abstract}

(C) Мухин С. В., 2020

Контент доступен под лицензией Creative Commons Attribution 4.0 License.

The content is available under Creative Commons Attribution 4.0 License. 
alongside with some resort to the procedure of phraseological identification. The word-list is made on the basis of scrutinizing the obligatory and optional phraseological traits of Old English word combinations. An account is taken of the lexicographic data found in the existing dictionaries of Anglo-Saxon lexicon. In choosing the sequence of entries it is proposed to follow the established tradition of phraseography. The structure of the entry is seen as including a number of mandatory elements, such as the headword, lemma, all the text-proven forms of the idiom, definition, a modern phraseological equivalent, if any, a few contextual examples of use and the idiom forms in Middle and New English. The recommendations worked out in the research are followed to present sample entries. Key words: phraseology, lexicography, Old English, dictionary, description.

\section{Введение}

В исследовательской практике особая роль принадлежит лексикографии. Трудно представить полноценный анализ лингвистических явлений без предварительной инвентаризации единиц языка. Это в равной степени справедливо применительно к исследованию современного и раннего состояния фразеологии английского языка. Вместе с тем на протяжении десятилетий в поле зрения составителей словарей преимущественно оказывался именно современный материал и продукты неологических процессов.

Одной из причин этого является общая неразработанность фразеологии в историческом аспекте. В отечественной англистике пик интереса к данной проблематике пришелся на 70-е гг. XX в., которые были отмечены несколькими исследованиями. Собственно древнеанглийской фразеологии были посвящены диссертация Н. А. Дьяковой [1] и монография А. А. Путина [2]. Еще несколько работ по исторической фразеологии английского языка были выполнены в иных хронологических рамках [3-5]. Ни одно из упомянутых исследований не было чисто лексикографическим. Исторический языковой материал в основном остался зафиксированным на страницах классических лексических словарей XIX в. Невозможно переоценить работу лексикографов той эпохи, однако факт состоит в том, что труд по систематическому описанию и кодификации единиц древнеанглийского лексикона проделывался, когда фразеологии как лингвистической дисциплины еще не существовало. Соответственно, древнеанглийская фразеология осталась обойденной вниманием; фразеологические единицы (ФЕ) приводятся в словарях древнеанглийского языка в основном в качестве примеров употребления лексем, являющихся компонентами ФЕ. Специальных фразеологических словарей древнеанглийского языка создано не было.

В качестве примера словарного представления устойчивого выражения в лексическом словаре древнеанглийского языка приведем словосочетание bearm scipes $^{1}$ (трюм, букв.: чрево корабля) в Bosworth - Tol-

1 Здесь и далее: орфография древнеанглийских единиц приводится в соответствии с отечественной учебно-исследовательской и издательской традицией, если не оговорено иное. ler Anglo-Saxon Dictionary (издание 1898 г.) [6]. Единица bearm scipes с высокой долей вероятности признается устойчивым словосочетанием в рамках формульной техники древнегерманского стихосложения [7, p. 41]. Данное словосочетание приводится в составе словарной статьи, посвященной существительному bearm (лоно, чрево). Информация, относящаяся к собственно ФЕ bearm scipes, представлена следующим образом:

Alédon leófne peóden on bearm scipes they laid the beloved chief in the ship's bosom, Beo. Th. 70; B. 35: Exon. 101b; Th. 382, 28; Rä. 4, $3^{2}$.

В таком виде рассматриваемое словосочетание представляет собой не более, чем контекстуальную иллюстрацию употребления лексемы bearm. Словарные пометы указывают на то, что приведенное словосочетание несколько раз встречается в тексте письменных памятников древнеанглийского периода: дважды в «Беовульфе» [8], а также в Уэссекских Евангелиях [9] и загадках Эксетерской книги [10], что служит косвенным подтверждением фразеологического статуса рассматриваемой единицы. В целом, такое представление ФЕ вряд ли может удовлетворить исследователя-фразеолога или историка языка.

В рамках настоящего исследования поставлена задача осветить основные лексикографические проблемы древнеанглийской фразеологии и выработать наиболее общие рекомендации по составлению фразеологического словаря древнеанглийского языка.

\section{Исследовательская часть}

Проблемы лексикографического описания достаточно многочисленны; некоторые из них максимально универсальны, другие имеют частный характер и возникают при описании единиц конкретных типов или составлении специальных словарей. В целях практической лексикографии проблемы можно распределить в следующие четыре основные группы: 1) параметризация словаря; 2) отбор единиц; 3) расположение отобранных единиц; 4) состав словарной статьи. Рассмотрим последовательно каждую группу проблем.

${ }^{2}$ Сохранена орфография источника. 


\section{Параметризащуия словаря}

Словарные параметры принято делить на теоретические и прагматические. К теоретическим параметрам, отражающим концепцию словаря, относят объект описания, типологические признаки словаря и его место в общей системе словарей. Прагматические параметры - адресат, хронологические рамки, обоснование словника, нормирование, источники, структура, объем информации, функциональные и стилистические квалификации, принципы иллюстрирования и т. п. - образуют текст словаря [11, с. 16].

Фразеологический словарь древнеанглийского языка имеет объектом описания древнеанглийские ФЕ и служит для фиксации состояния фразеологической подсистемы английского языка в VII-XI вв. Типологически он совмещает черты фразеологического и исторического словарей. Целевой аудиторией словаря предполагаются филологи, специалисты по фразеологии, истории и этимологии английского языка. Поскольку изучение перечисленных дисциплин невозможно без владения современным английским языком, то логичным видится выбор типа словаря как толкового, а не переводного. Состав словника ограничивается объемом доступного материала в максимальном количестве древнеанглийских текстов. Каждая словарная единица иллюстрируется двумя-тремя контекстуальными примерами ее употребления в тексте.

Серьезную проблему представляет собой нормирование словаря, поскольку речь идет о конкретном материале, функционировавшем в эпоху, когда общенациональной языковой нормы не существовало. Так, адвербиальная ФЕ со значением «всегда» (букв.: «рано и поздно») засвидетельствована в текстах в следующих формах, различающихся по орфографическим, лексическим и структурным (порядок слов) признакам: 1) oer ond sið; 2) cer and sip; 3) sip and oer; 4) syp oððе cer; 5) sume cer, sume sip. В такой ситуации представляется оправданным включать в состав соответствующей словарной статьи все письменно зафиксированные варианты ФЕ.

\section{Отбор единиц}

Отбор словарных единиц для фразеологического словаря древнеанглийского языка представляет собой наиболее трудоемкую часть лексикографического описания. Самой сложной задачей при этом является идентификация древнеанглийских ФЕ как таковых. Представляется, что фразеологический метод А. В. Кунина [12], разработанный преимущественно для изучения фразеологии современного языка, в основных своих положениях применим к древнеанглийскому материалу. Некоторые словосочетания в древнеанглийских текстах явно демонстрируют признаки связанности, позволяющие применить к таким словосочетаниям процедуры фразеологической идентификации. Среди таких признаков можно выделить облигаторные и факультативные.

К первым относятся раздельнооформленность, фразеологическая устойчивость и воспроизводимость, единство синтаксической функции. Словосочетание или сложная языковая единица, не имеющие всех облигаторных признаков, не могут быть признаны фразеологизмами.

Так, форма scir(-) зегеаfa (судебный надзиратель административной территории, префект, иериф) не удовлетворяет критериям раздельнооформленности, являясь композитным лексическим образованием, на что указывает морфологическая неоформленность первого элемента, который в составе раздельнооформленного словосочетания должен был бы находиться в форме генитива scire zereafa (букв.: надзиратель округа; shire's reeve; sheriff). Не имея морфологических формантов и будучи неизменяемым, данный элемент представляет собой одну из основ сложного существительного. У предложноименных фразеоматических сочетаний морфологическое оформление знаменательного компонента выступает единственным показателем раздельнооформленности, если не учитывать фактор орфографии, например: to soðе (истинно; взаправду), где существительное soð (правда), подчиняясь предложному управлению, принимает форму датива.

Воспроизводимость ФЕ в древнеанглийских текстах чрезвычайно важна, поскольку в лексикографической практике главным критерием отграничения языковых единиц от речевых словосочетаний выступает их «повторяемость в различных текстах в типовых связях с одинаковыми или близкими по значению словами» $[13$, с. 300]. Так, выражение зrundwonz ofзyfan (умереть, букв.: оставить землю) засвидетельствовано в тексте только дважды, и оба раза в эпосе «Беовульф», что делает проблематичным подтверждение его фразеологического статуса. В то же время в таких письменных памятниках, как Genesis и поэма «Скиталец», зафиксированы синонимичные выражения woruld of $3 y$ fan (покинуть мир) [14] и flet of 3yfan [10] (покинуть обитель), которые можно рассматривать как варианты единой ФЕ.

Единство синтаксической функции ФЕ является абсолютно необходимым признаком. Фразеологизм всегда выступает в предложении как единое синтаксическое целое, например: poet we synna and mandceda forleton and soo and riht dydon pa hwile, pe we on pyssum laenan life beon [15] (чтобы мы грехи и злодеяния оставили и следовали правде и закону всю нашу недолгую жизнь ${ }^{3}$, где субстантивная ФЕ sоð

$$
\text { C. } M \text {. }
$$

3 Здесь и далее: перевод наш, если не оговорено иное. - 
and riht (правда и закон) выступает как прямое дополнение к сказуемому, выраженному глаголом don (делать), а ФЕ on life beon (жить; быть в живых) представляет собой сказуемое придаточного предложения.

Для собственно фразеологизмов с идиоматическим значением облигаторным признаком является переосмысление значения всех или отдельных компонентов, например ФЕ to handa (во власть; в подчинение), в составе которой лексема hand (рука) претерпевает метафорическое переосмысление значения. У ФЕ sweordum aswebban (убить, букв.: ycbпить мечом) следует констатировать переосмысление глагольного компонента. Переосмысление, в частности, всегда характерно для сверхсловных кеннингов, например: hwceles eðеl (море, букв.: родина китов), где существительное eðеl (родина, отчизна, дом), изначально обозначающее понятие из сферы человеческих и общественных отношений, употребляется по отношению к животным.

Факультативными признаками ФЕ выступают словарная фиксация, различного рода системные отношения между компонентами, аллитерация и любое созвучие компонентов, морфологическое единообразие компонентов, наличие гетерохронных фразеологических вариантов. Так, в лексическом словаре Bosworth-Toller приводится словосочетание yðа зеwеalc (волн перекат), которое отмечено не менее 14 раз в нескольких различных произведениях, что свидетельствует о его регулярном использовании. Отношения синонимии компонентов в словосочетании idel and unnyt (nycтой и бесполезный) говорят в пользу фразеологического статуса последнего. Единство морфологического оформления компонентов и аллитерацию можно видеть в следующих примерах: bearn ond bryde (дети и женщзины), где оба компонента находятся в форме номинатива множественного числа, или в словосочетании forzytan ond forzyman (забыть и не вспоминать), где оба глагольных компонента в контексте всегда принимают одну и ту же грамматическую форму и представляют собой дериваты с одним превербом for-. Гетерохронность ФЕ лучше всего прослеживается на примере евангельских единиц, последовательно представленных в текстах всех трех основных периодов истории английского языка, например: lot deade bebyrizean hyra deadan > late dede men birye her dead men > let the deed burie their deed [16] (nусть мертвые хоронят своих мертвецов (Мф. 8:22); кто старое помянет, тому глаз вон).

\section{Расположение отобранных единии}

Относительно расположения словарных единиц в словаре представляется, что правила, выработанные для фразеологических словарей синхронного типа, вполне применимы к словарю древнеанглийской фразеологии. Порядок расположения определяется двумя факторами: последовательностью букв в алфавите и набором вокабул - константных (неподменяемых или не подлежащих эллипсису) компонентов ФЕ, которые вводят словарные статьи [17]. Чаще всего вокабулами являются имена существительные. Поскольку не у всех ФЕ возможно выделить грамматический или семантический стержень, признак константности компонента - единственно возможный.

Приведем несколько примеров. Для ФЕ структурного типа $\mathrm{V}+\mathrm{N}$ субстантивные компоненты всегда будут вокабулами, например: wordhord onlucan (заговорить, букв.: открыть сокровищнииу слов) - вокабула wordhord. Для двухкомпонентных субстантивных, адъективных, глагольных и адвербиальных ФЕ, компоненты которых равноценны семантически, в качестве вокабулы выбирается первый компонент, например: zamen ond zleodream (удовольствие $и$ развлечение) - вокабула затеп (радость, удовольствие); forsidian ond forsweorcan (гибнуть и меркнуть) - вокабула forsiðian (гибнуть) и т. п. У фразеоматических единиц семантический стержень, представленный, как правило, существительным, можно выделить достаточно четко, например: on slape (во сне) - вокабула slcep (сон); mid eallum mode (от всей души) - вокабула mod (душа) и т. п. Значительную сложность представляет определение вокабулы для предикативных единиц. В таких случаях единственно возможным представляется формальный подход - в качестве вокабулы используется первый знаменательный компонент: Đa пе sacað pe cetsamne пе ьеоð ${ }^{4}$ (Те не ссорятся, кто не вместе) - вокабула sacan (ccopumbca); Swa fulre faet, swa hit mann sceal faеzror beran (Чем полнее чаша, тем осторожней ее надо нести) - вокабула ful (полный); Wide ne bip wel, cwap se pe zehyrde on helle hriman ( ВВезде непорядок», сказал тот, кто усльишал крики в аду) - вокабула wide (везде, повсюду) и т. п.

\section{Состав и структура словарной статьи}

Проблема определения состава и структуры словарной статьи предполагает выполнение целого ряда практических задач, среди которых основными являются следующие: лемматизация, отбор и расположение значений; составление дефиниций; выбор примеров употребления. Для фразеологического словаря древнеанглийского языка также представляется необходимым приведение гетерохронных фразеологических форм.

Достаточно серьезную проблему представляет лемматизация - определение словарной формы ФЕ древнеанглийского языка при его общей весьма низкой нормированности и высокой вариативности. Эта

${ }^{4}$ Пословицы цитируются по [18]. 
проблема еще более осложняется комплексным характером самих рассматриваемых единиц. При выборе леммы из нескольких форм следует руководствоваться следующими соображениями:

1) стуктура леммы должна быть максимально проста и коротка. Например, у глагольных ФЕ выбор всегда следует сделать в пользу номинативной формы инфинитива tredan wraclastas (скитаться на чужбине, букв.: топтать стези изгнания), а не дативной to tredenne wroeclastas;

2) леммой должен быть наиболее частотный вариант ФЕ. Так, из вариантов Zodes condel и Zodes condelle (солнце, букв.: божья свеча) выбору подлежит первый, поскольку отмечено семь случаев употребления данной формы, тогда как вторая встречается только дважды [6];

3) при наличии вариантов, равноценных во всех отношениях, практикуется алфавитный порядок: в качестве леммы выбирается вариант, первый знаменательный компонент которого идет раньше по алфавиту, чем у других вариантов, например при сравнении следующих вариантов ФЕ unclana zast = se werza зсеst (нечистый $\partial y x$, злой $у y x$ ) предпочтение отдается первому.

Представляется, что существенным фактором лемматизации также является лексикографическая традиция. Так, адъективные единицы традиционно принято представлять в форме номинатива мужского рода, и, даже если такая форма не зафиксирована, для удобства пользователей следует давать в качестве леммы именно ее. Например, в тексте имеем: $c y m e p$ to demenne cwicum ond deadum (грядет судить живых и мертвых), а также to demenne aеzдеr zе дат cисит зе бат deadum (судить как живых, так и мертвых) - в словаре даем лемму cwican and deadan (живые и мертвые; все человечество).

Важным, хотя и косвенным, доказательством фразеологического статуса древнеанглийских словосочетаний выступает факт наличия структурно и семантически схожих форм в последующие периоды развития языка. В этом случае можно говорить об этимологическом тождестве языковой единицы [19], существующей во времени. Эта информация представляет существенную ценность для диахронических исследований и, безусловно, должна присутствовать в словарной статье в виде средне- и новоанглийской форм соответствующей $Ф Е$.

В качестве примеров таких гетерохронных форм ФЕ можно привести следующие единицы: se ðе secp, he hyt fint $>$ he that sechith, fyndith > he that seketh, fyndeth (ищущий обрящет); tida tacnu > the tokenys of tymes $>$ the sygnes of the tymes (знамение времени) [16]; pritiz scyllinza $>$ thritti platis of seluer $>$ thirty peces of sylver (тридиать сребренников) и т. п.
Достаточно распространенную разновидность этимологического тождества следует также констатировать у несвободных словосочетаний, которые впоследствии подверглись лексикализации, например, Saternes daez > Sater-dai > Saturday (cуббота); dazes eaze > daies-ie > daisy (маргаритка, Bellis perennis $)^{5}$ и т. п. К последним также относятся предложно-именные словосочетания с адвербиальным значением: to merzenne > tomorwe > tomorrow (завmpa); on wez $>$ awei $>$ away (прочb); on flote $>$ aflote $>$ afloat (на море, в плавании) и др.

Вопрос отбора и расположения значений в словарной статье фразеологического словаря древнеанглийского языка не является первостепенным. Подавляющее большинство единиц реализуют в текстах только одно значение. Исключение могут составлять те ФЕ, интерпретация которых вызывает сомнения, например единица metan merestrceta (букв.: мерять морские дороги) в следующем контексте из «Беовульфа»: on sund reon por zit eazorstream earmum pehton maeton merestraeta mundum bruзdon (проливом гребли, вы потоки морские в объятьях держали, меряли море, руками трудясь). Обычно данный эпизод трактуется как состязание пловцов ${ }^{6}$, хотя контекст допускает возможность того, что речь идет о лодочной гонке, на что указывает употребление глагола rowan. Соответственно, выражение metan merestrceta может иметь как значение «передвигаться вплавь (to swim)», так и «плыть на лодке или корабле (to sail; to navigate)». В таких случаях следует приводить оба значения с пометой possibly.

Поскольку предполагаемый фразеологический словарь не относится к двуязычному типу, дефиниции $Ф Е$, очевидно, должны представлять собой лексемы, или свободные словосочетания, или ФЕ современного английского языка. Впрочем, структурная и типологическая разница между древне- и новоанглийским языком столь велика, что современные дефиниции такого рода можно трактовать как перевод, например: fon to rice = come to power; don yfele = to harm; zеozop buton ylde = youth without age и т. п.

Следуя традиционному подходу к иллюстрированию словарных единиц во фразеологических словарях, представляется оправданным давать два-три примера контекстуального употребления ФЕ из различных источников, например:

ФЕ ар swerian (приносить клятву):

he ab swerep purh his selfes lif (он клянется собственной жизнью). Пример из метрического перифраза частей Священного Писания, выполненного Кэдмоном [22].

\footnotetext{
${ }^{5}$ Среднеанглийские формы приводятся по [20].

${ }^{6} \mathrm{Cp}$. перевод В. Тихомирова: «Пучин теченья сеча руками, взмахами меряя море-дорогу, вы плыли по волнам» [21].
} 
on ðат daезе ðе mon ðа аðаs swor (в тот день, когда были принесены клятвы). Пример из договора короля Альфреда с данами [23].

him pa apas sworon on pam halzan beaze (eмy клятвы принесли на святом кольце). Пример из Англосаксонской хроники [24].

При такой подаче примеров указание на источники должно присутствовать в обязательном порядке, что продиктовано практическими соображениями удобства потенциальных пользователей словаря.

\section{Методика составления словарной статьи}

Рассмотрим, как могла бы выглядеть словарная статья для субстантивной ФЕ евангельского происхождения wop and topa zristbitunz (плач и скрежет зубовный/зубов) во фразеологическом словаре древнеанглийского языка для специалистов по истории языка и фразеологии, владеющих современным английским языком:

\section{WOP}

\section{№ ... Bible. WOP AND TOPA 3RISTBITUN3}

1) wop and/ond topa/toða/topene zristbitunz; 2) wop \& topa zryst-lunz.

Pain, despair, suffering. = Weeping and gnashing of teeth.

Witodlice ðises rices beam beoð aworpene on pa ytemestan pystro: ðcer by $p$ wop, and topa zristbitunz (Mt 8:12).

But the children of the kingdom shall be cast out into outer darkness: there shall be weeping and gnashing of teeth.

Dar bið wop \& topazryst-lunz poenne zе zеseop Abraham \& Isaac \& Iacob \& ealle witezan on Godes rice \& ze beod utadrifene (Lk 13:28).

There shall be weeping and gnashing of teeth, when ye shall see Abraham, and Isaac, and Jacob, and all the prophets, in the kingdom of God, and you yourselves thrust out ${ }^{7}$.

... ða eacen witu, par bið eazena wop ond topa zristbitunz ond welera durst ... (Homilies).

... the eternal torment, where shall be weeping of eyes, and gnashing of teeth, and thirst of lips ...

$M E$ weepynge, and betyng to gidre of teeth; $N E$ wepynge, and gnasshinge of theth.

Элементы словарной статьи расположены построчно. Показателем каждого элемента является отступ строки. Словарную статью предваряет вокабула, в качестве которой в данном случае выбрано существительное wop. Выбор обусловлен тем, что данная лексема является единственным знаменательным неизменяемым компонентом во всех вариантах ФЕ.

${ }^{7}$ Перевод первых двух примеров в статье дается по Библии короля Иакова [25].
Далее следует порядковый номер статьи в словаpe, этимологическая помета Bible, указывающая на библейское происхождение ФЕ, и лемма самой ФЕ в наиболее частотной форме.

В следующей строке пронумерованным списком приводятся все письменно зафиксированные диалектные варианты ФЕ, причем морфологические и орфографические варианты компонентов даны через косую черту, а варианты ФЕ с различающимися лексическими компонентами идут под соответствующим порядковым номером и разделяются точкой с запятой.

Приведена дефиниция, которая дана в виде ряда синонимичных существительных, и фразеологическое соответствие древнеанглийской ФЕ в современном английском языке.

Иллюстративные примеры даны в количестве трех. Первые два представляют собой стихи из Евангелий от Матфея и Луки, в которых употребляются этимоны рассматриваемой ФЕ. Если контексты с этимонами имеются в различных Евангелиях, представляется правильным приводить именно примеры из различных источников. Примеры снабжены пометами, указывающими на конкретные Евангелия, главы и стихи, и переводом на современный английский язык. Третий пример взят из одного из кратких агиографических произведений, характерных для древнеанглийской гомилетики [26, р. 58], на что указывает помета Homilies.

В последней строке приводятся фразеологические соответствия древнеанглийской ФЕ в средне- и новоанглийском периодах.

Этимология фразеологизмов библейского происхождения довольно специфична, а сфера функционирования часто ограничена собственно библейскими текстами. Это неизбежно налагает отпечаток на лексикографическое представление таких единиц. Рассмотрим для сравнения, как можно представить словарную статью небиблейской ФЕ frip niman (wið) (заключить мир (c)):

\section{FRIĐ}

№ ... FRIĐ NIMAN (WIĐ)

1) frið/frip (ze)niman/don/habban/healdan (wið); 2) (ze)niman/don/habban/healdan frið/frip (wið).

1. To make peace (with), to reconcile, to bury the hatchet. 2. euph. To grudgingly accept the terms, to put up with, to submit = to take it lying down.

He nam frip wid ðat folc

He made peace with the people (Orosius)

Mierce frip namon wip pone here (AS Chronicle A868)

Mercians concluded peace with the army

... hi him poer forezislas saldon swa fela swa he habban wolde, \& mycle apas sworon, \& pa zodne frip heoldon ... (AS Chronicle D877) 
... they gave him as many hostages as he would have, and swore solemn oaths, and made a sustainable peace ...

$M E$ make(n) pais (with); $N E$ to make peace (with).

Остановимся лишь на тех особенностях лексикографической репрезентации рассматриваемой $Ф \mathrm{E}$, которые отличаются от приведенных выше для единицы wop and topa zristbitunz.

В качестве вокабулы выбрано существительное frið как демонстрирующее наименьшую вариативность из всех компонентов $Ф Е$.

Лемма ФЕ включает предлог wið, данный в скобках, что указывает на его контекстуальную факультативность.

Характерной особенностью рассматриваемой ФЕ является вариативность. В древнеанглийских письменных памятниках зафиксированы варианты don frið, habban frið, (зe)niman frið, healdan frið. В литературе отмечается $[27$, p. 48] семантическая эквивалентность варьирующих глагольных компонентов в составе фразеологизма. В словарной статье элементами нумерованного списка выступают варианты $Ф \mathrm{E}$, различающиеся порядком слов.

Дефиниции приводятся для двух значений древнеанглийской $Ф Е$. Первое значение определяется через современный фразеологический эквивалент, синонимичную глагольную лексему и синонимичную $Ф Е$ современного английского языка. Второе значение предваряется пометой, указывающей на то, что рассматриваемая ФЕ использовалась в качестве эвфемизма и означала «быть вынужденным принять тяжелые условия победителя» [28, p. 98]. Значение определяется через свободное словосочетание, синонимичный глагол, синонимичный фразовый глагол и синонимичную $Ф Е$ современного английского языка.

Иллюстративные примеры взяты из англосаксонской версии «Истории мира» Орозия [29] и Англосаксонской хроники с указанием конкретных манускриптов и соответствующих анналов [24].

\section{Выводы}

Ограниченный объем языкового материала и общая неразработанность исторической фразеологии английского языка ставят ряд проблем общего и частного характера, которые необходимо решить при составлении фразеологического словаря древнеанглийского языка. Как можно видеть из приведенного анализа, центральные проблемы не являются лексикографическими per se, а относятся к сфере собственно фразеологии. Самой насущной из них следует признать отождествление древнеанглийских ФЕ. Практика показывает, что задача отбора ФЕ для словаря в значительной степени осуществима при помощи метода фразеологической идентификации, анали- за памятников письменности и лексикографических данных классических словарей древнеанглийской лексики. Даже тот сравнительно небольшой языковой материал, который сохранился в древних текстах, позволяет составить впечатление о богатстве и разнообразии древнеанглийского фразеологического фонда при условии его должной лексикографической систематизации.

\section{ЛИТЕРАТУРА}

1. Дьякова Н. А. Устойчивые словесные комплексы древнеанглийской оригинальной прозы : автореф. дис. ... канд. филол. наук. Л., 1977. 23 с.

2. Путин А. А. Об устойчивых сочетаниях слов в древнеанглийском языке. Пермь, 1974. 223 с.

3. Владимириева А. Г. Становление и развитие устойчивых словосочетаний с глаголами to take и to give в английском языке : автореф. дис. ... канд. филол. наук. M., $1971.18 \mathrm{c}$.

4. Начисчионе А. С. Окказиональное стилистическое использование фразеологических единиц : (на материале произведений Дж. Чосера) : автореф. дис. ... канд. филол. наук. М., 1976. 21 с.

5. Карпова И. П. Становление и развитие английских фразеологических единиц с XIV по XX в. : дис. ... канд. филол. наук. М., 1979. 237 с.

6. Bosworth and Toller. An Anglo-Saxon dictionary, based on the manuscript collections of the late Joseph Bosworth; edited and enlarged by T. Northcote Toller. URL: https://www.ling.upenn.edu/ kurisuto/germanic/oe_bosworthtoller_about.html

7. Tyler E. M. Old English Poetics: The Aesthetics of the Familiar in Anglo-Saxon England. 2006. Boydell \& Brewer. $194 \mathrm{p}$

8. Beowulf. Diacritically Marked Text and Facing Translation. URL: https://heorot.dk/beowulf-rede-text.html

9. Thorpe B., Klipstein L. F. Tha Halgan Godspel on Englisc: the Anglo-Saxon Version of the Holy Gospels. New York, $1846.259 \mathrm{p}$.

10. Thorpe B. Codex Exoniensis. A Collection of Anglo-Saxon Poetry, from a Manuscript in the Library of the Dean and Chapter of Exeter. London, 1842. 575 p. URL: https://archive.org/details/codexexoniensis01londgoog/ page/n9

11. Скляревская Г. Н. Новый академический словарь : объект, типологические признаки, место в системе русской лексикографии // Очередные задачи русской академической лексикографии. СПб., 1995. С. 15-23.

12. Кунин А. В. Курс фразеологии современного английского языка. М. : Высшая школа ; Дубна : Феникс, 1996. $381 \mathrm{c}$.

13. Дубичинский В. В. Лексикография русского языка : учеб. пособие. М. : Наука: Флинта, 2008. 432 с.

14. Genesis A. URL: https://web.archive.org/ web/20181206091232/http://ota.ox.ac.uk/desc/3009

15. Scragg $D$. G. The corpus of vernacular homilies and prose saints' lives before Ælfric. Cambridge University 
Press, 2008. URL: https://www.cambridge.org/core/journals/anglo-saxon-england/article/corpus-of-vernacularhomilies-and-prose-saints-lives-before-aelfric/CA183724D741F57A242216897A5EF1BF

16. Bosworth J. Gothic and Anglo-Saxon Gospels in Parallel Columns with the Versions of Wycliff and Tyndale. London, 1888. URL: https://archive.org/stream/gothicandanglos00ulfigoog\#page/n8/mode/2up

17. Кунин А. В. Большой англо-русский фразеологический словарь. М. : Живой язык, 1998. 942 с.

18. Arngart O. The Durham Proverbs. Speculum. 1981. Vol. 56, No. 2. Pp. 288-300.

19. Смирницкий А. И. Древнеанглийский язык. М. : МГУ, 1998. 319 с.

20. Middle English Compendium. URL: https://quod. lib.umich.edu $/ \mathrm{m} / \mathrm{middle}$-english-dictionary

21. Беовульф / пер. В. Тихомирова. URL: http://mifolog.ru/books/item/f00/s00/z0000007/st001.shtml

22. Cædmon's Metrical Paraphrase of Parts of the Holy Scripture in Anglo-Saxon. London, 1832. 341 p.

23. Attenborough F. L. The Laws of the Earliest English Kings. Cambridge, 1922. 256 p.

24. Anglo-Saxon Chronicle. URL: http://asc.jebbo. co.uk/intro.html

25. King James Bible Online. URL: https://www.kingjamesbibleonline.org/

26. Wright Ch. D. More Latin Sources for the Old English "Three Utterances Homilies". URL: https://pims.ca/ wp-content/uploads/2019/11/ms77-45.pdf (accessed: 03.06.2020).

27. Brinton L. J., Akimoto M. Collocational and Idiomatic Aspects of Composite Predicates in the History of English. John Benjamins Publishing, 1999. 283 p.

28. Konshuh $C$. Fighting with a lytle werode: Alfred's Retinue in the Anglo-Saxon Chronicle // Medieval Chronicle X. Leiden: Brill, 2016. 332 p.

29. King Alfred's Anglo-Saxon Version of the Compendious History of the World by Orosius. Ed. by J. Bosworth, London, 1859. $505 \mathrm{p}$.

\section{REFERENCES}

1. D'yakova N. A. Ustojchivye slovesnye kompleksy drevneanglijskoj original'noj prozy [Fixed Word Complexes of Old English Original Prose]: avtoref. ... kand. filol. n. Leningrad, 1977. $23 \mathrm{p}$.

2. Putin A. A. Ob ustojchivyh sochetaniyah slov v drevneanglijskom yazyke [On Fixed Word Combinations in Old English]. Perm', 1974. 223 p.

3. Vladimirceva A. G. Stanovlenie i razvitie ustojchivyh slovosochetanij s glagolami to take $i$ to give $v$ anglijskom yazyke [Rise and Development of Fixed Word Combinations with the Verbs to Take and to Give in English]: avtoref. dis. ... kand. filol. nauk. Moscow, 1971. 18 p.

4. Nachischione A. S. Okkazional'noe stilisticheskoe ispol'zovanie frazeologicheskih edinic: (na materiale proizvedenij Dzh. Chosera) [Occasional Stylistic Use of Phraseological Units (Exemplified by G. Chaucer's Works] avtoref. dis. ... kand. filol. n. Moscow, 1976. 21 p.
5. Karpova I. P. Stanovlenie i razvitie anglijskih frazeologicheskih edinic s XIV po XXv. [Rise and Development of English Phraseological Units from $14^{\text {th }}$ to $20^{\text {th }}$ Centuries]: diss. ... kand. filol. n. Moscow, 1979. 237 p.

6. Bosworth and Toller. An Anglo-Saxon dictionary, based on the manuscript collections of the late Joseph Bosworth; edited and enlarged by T. Northcote Toller. Available at: https://www.ling.upenn.edu/ kurisuto/germanic/oe_bosworthtoller_about.html

7. Tyler E. M. Old English Poetics: The Aesthetics of the Familiar in Anglo-Saxon England. 2006. Boydell \& Brewer. 194 p.

8. Beowulf. Diacritically Marked Text and Facing Translation. Available at: https://heorot.dk/beowulf-rede-text.html

9. Thorpe B., Klipstein L. F. Tha Halgan Godspel on Englisc: the Anglo-Saxon Version of the Holy Gospels. New York. 1846.259 p.

10. Thorpe B. Codex Exoniensis. A Collection of Anglo-Saxon Poetry, from a Manuscript in the Library of the Dean and Chapter of Exeter. London, 1842.575 p. Available at: https://archive.org/details/codexexoniensis01londgoog/ page/n9

11. Sklyarevskaya G. N. Novyj akademicheskij slovar': ob"ekt, tipologicheskie priznaki, mesto v sisteme russkoj leksikografii [New Academic Dictionary: Object, Typological Features, Place in the System of Russian Lexicography] // Ocherednye zadachi russkoj akademicheskoj leksikografii. SPb., 1995. Pp. 15-23.

12. Kunin A. V. Kurs frazeologii sovremennogo anglijskogo yazyka [A Course of Modern English Phraseology]. Moscow: Vysshaya shkola, Dubna: Izd. centr «Feniks», 1996. $381 \mathrm{p}$

13. Dubichinskij V. V. Leksikografiya russkogo yazyka [Lexicography of Russian]: Ucheb. posobie. Moscow: Nauka: Flinta, 2008. 432 p.

14. Genesis A. Available at: https://web.archive.org/ web/20181206091232/http://ota.ox.ac.uk/desc/3009

15. Scragg D. G. The corpus of vernacular homilies and prose saints' lives before Alfric. Cambridge University Press. 2008. Available at: https://www.cambridge.org/core/ journals/anglo-saxon-england/article/corpus-of-vernacularhomilies-and-prose-saints-lives-before-aelfric/CA183724D741F57A242216897A5EF1BF

16. Bosworth J. Gothic and Anglo-Saxon Gospels in Parallel Columns with the Versions of Wycliff and Tyndale. London, 1888. Available at: https://archive.org/stream/ gothicandanglos00ulfigoog\#page/n8/mode/2up

17. Kunin A. V. Bol'shoj anglo-russkij frazeologicheskij slovar' [Big English-Russian Phraseological Dictionary]. Moscow: Zhivoj yazyk, 1998. 942 p.

18. Arngart O. The Durham Proverbs. Speculum. 1981. Vol. 56, No. 2. Pp. 288-300.

19. Smirnickij A. I. Drevneanglijskij yazyk [Old English]. Moscow: MGU, 1998. 319 p.

20. Middle English Compendium. Available at: https:// quod.lib.umich.edu/m/middle-english-dictionary 
21. Beovul'f. Perevod V. Tihomirova. Available at: http://mifolog.ru/books/item/f00/s00/z0000007/st001.shtml

22. Cædmon's Metrical Paraphrase of Parts of the Holy Scripture in Anglo-Saxon. London, 1832. 341 p.

23. Attenborough F. L. The Laws of the Earliest English Kings. Cambridge, 1922. 256 p.

24. Anglo-Saxon Chronicle. Available at: http://asc. jebbo.co.uk/intro.html

25. King James Bible Online. Available at: https://www. kingjamesbibleonline.org/

Московский государственный институт международных отношений МИД России

Мухин С. В., кандидат филологических наук, дочент кафедры английского языка № 1

E-mail: s.muhin@inno.mgimo.ru

Поступила в редакиию 25 июня 2020 г.

Принята к публикаџии 25 сентября 2020 2.

\section{Для цитирования:}

Мухин С. В. Фразеология древнеанглийского языка: проблемы лексикографического описания // Вестник Воронежского государственного университета. Серия: Лингвистика и межкультурная коммуникация. 2020. № 4 . C. 66-74. DOI: https://doi.org/10.17308/lic.2020.4/3081
26. Wright Ch. D. More Latin Sources for the Old English "Three Utterances Homilies". Available at: https:// pims.ca/wp-content/uploads/2019/11/ms77-45.pdf

27. Brinton L. J., Akimoto M. Collocational and Idiomatic Aspects of Composite Predicates in the History of English. John Benjamins Publishing, 1999. 283 p.

28. Konshuh C. Fighting with a lytle werode: Alfred's Retinue in the Anglo-Saxon Chronicle. In: Medieval Chronicle X. Leiden: Brill, 2016. 332 p.

29. King Alfred's Anglo-Saxon Version of the Compendious History of the World by Orosius. Ed. by J. Bosworth, London, 1859. 505 p.

Moscow State Institute of International Relations of the Foreign Ministry of Russia

Mukhin S. V., Candidate of Philology, Associate Professor of the English Language Department № 1

E-mail: s.muhin@inno.mgimo.ru

Received: 25 June 2020

Accepted: 25 September 2020

\section{For citation:}

Mukhin S. V. Old English phraseology: problems of lexicographic description. Proceedings of Voronezh State University. Series: Linguistics and Intercultural Communication. 2020. No. 4. Pp. 66-74. DOI: https://doi.org/10.17308/ lic. $2020.4 / 3081$ 